\title{
Uso de un Injerto Autólogo de Grasa para la Corrección de Asimetrías Faciales y Corporales
}

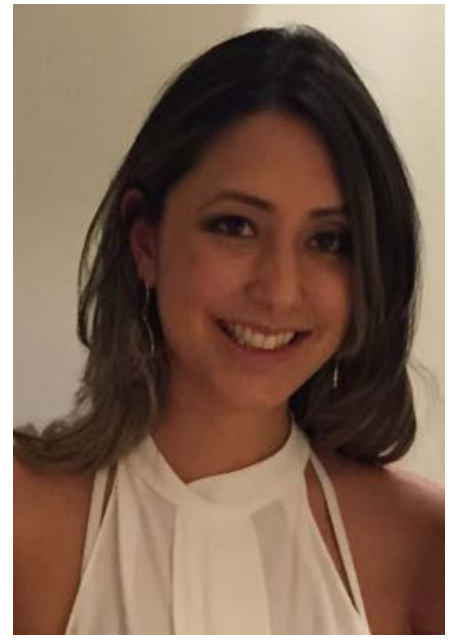

Autor: Dra. Daniela Centurion Shirata (Médico Residente de los Servicios Integrados de Cirugía Plástica Hospital lpiranga)

Coautor: Dra. Aline Franco Goto (Médico Residente de los Servicios Integrados de Cirugía Plástica Hospital lpiranga)

Dra. Lilian Isabela Duque de Souza (Médico Residente de los Servicios Integrados de Cirugía Plástica Hospital Ipiranga); Dr. Marcelo Borges Buscariolli (Médico auxiliar de enseñanza de los Servicios Integrados de Cirugía Plástica Hospital Ipiranga); Dr. Silvio Frizzo Ognibene (Médico Orientador de enseñanza de los Servicios Integrados de Cirugía Plástica Hospital Ipiranga); Dr. José Octávio Gonçalves de Freitas (Regente de los Servicios Integrados de Cirugía Plástica Hospital lpiranga)

Localidad: Servicios Integrados de Cirugía Plástica Hospital Ipiranga- São Paulo-Brasil

\section{Resumen}

Objetivos: evaluar el grado de corrección de asimetrías en el rostro y en el cuerpo debido a traumas, enfermedades congénitas o adquiridas, así como el uso de lipo-injerto, por medio de un examen físico y por fotografías.

Materiales y métodos: la técnica utilizada en nuestro servicio se basa en los estudios de coleman. La documentación se realiza por medio de prontuario y fotografías, durante el pre, trans y pos operatorio de 1,3, 6 y 12 meses. Resultados: notamos que además de la mejoría en las retracciones cicatriciales y el aumento del volumen en áreas de depresión, la infiltración de grasa proporcionó la mejoría de la calidad de la piel. El volumen de grasa parece que necesita aproximadamente de 3 meses para estabilizarse. Con el acompañamiento de hasta un ano, notamos que a través de un examen físico y de fotografías, hubo poca reabsorción del injerto y mantenimiento del volumen. Conclusión: a través de exámenes clínicos de los pacientes sometidos al procedimiento en nuestro servicio, fue posible comprobar resultados satisfactorios y estimulantes en relación a la permanencia de la grasa injertada.

\section{Abstract}

Objectives: to evaluate the degree of 
correction of asymmetries in the face and body due to trauma, congenital or acquired diseases, as well as the use of lipo-graft, through physical examination and photographs. Materials and methods: the technique used in our service is based on coleman's studies. The documentation is done by means of medical records and photographs, during the pre, trans and post operative of $1.3,6$ and 12 months.results: we noticed that in addition to the improvement in scar retractions and the increase in volume in areas of depression, fat infiltration provided the improvement of skin quality. The volume of fat seems to need about 3 months to stabilize. With the accompaniment of up to one year, we noticed that through a physical examination and photographs, there was little reabsorption of the graft and maintenance of the volume. Conclusion: through clinical examinations of the patients submitted to the procedure in our service, it was possible to verify satisfactory and stimulating results in relation to the permanence of the grafted fat.

\section{Introducción}

La lipo-injerto ha sido utilizada desde 1893, cuando Neuber describió el uso de grasa de brazo para la reconstrucción de defectos faciales de tejido blando ${ }^{1}$.

En la década de los 80 , la liposucción proporcionó un valioso bio producto a los cirujanos plásticos: la grasa semi líquida que podría ser injertada con relativa facilidad usando agujas $y$ pequeñas cánulas 2 .

En 1994, Coleman describió por primera vez su técnica usando jeringa, cánula y centrífuga con el objetivo de realizar un injerto de grasa estructurado $^{5-6}$. Lo mismo ha demostrado que la centrifugación es importante para el mantenimiento de la grasa inyectada 7 .

El injerto de grasa exhibe varias calidades de un llenador ideal: es autólogo y bio compatible, presente en cantidad suficiente en la mayor parte de los pacientes, tiene una integración natural a los tejidos huéspedes y puede ser removido en caso de ser necesario ${ }^{2}$. La permanencia de estos injertos es controversial.

\section{Objetivos}

Evaluar la evolución de la grasa inyectada en pacientes atendidos en los Servicios Integrados de Cirugía Plástica - SICP-HI, por medio de un examen físico y por fotografías.

Evaluar el grado de corrección de asimetrías en el rostro y en el cuerpo debido a traumas, enfermedades congénitas o adquiridas, así como el uso de lipo-injerto.

\section{Materiales y Métodos}

La técnica utilizada en nuestro servicio se basa en los estudios de Coleman. El material se obtiene a través de liposucción de las áreas donde existe mayor distribución de grasa en cada paciente, las cuales ya fueron marcadas 
previamente. La anestesia utilizada se elige entre local o general, dependiendo de la localización y de la cantidad de grasa necesaria, así como las condiciones clínicas de los pacientes. Se realiza una infiltración con solución de Klein, antes de la liposucción. La succión del tejido adiposo se hace con cánulas de $203 \mathrm{~mm}$ de diámetro en jeringas de $10 \mathrm{cc}$. La grasa obtenida es centrifugada a una velocidad de 3000 rotaciones por minuto durante 3 minutos, en centrífuga eléctrica.

La centrifugación separa los componentes de acuerdo a su densidad. Después de la centrifugación, el material succionado se divide en tres partes: la camada superior es la menos densa, constituida básicamente de óleo; la porción medial es el tejido grasiento; y la última camada se compone por sangre, agua y elementos acuosos.

El suero y el exceso de óleo son descartados, utilizando únicamente los adipocitos centrifugados. Se realizan incisiones de $2 \mathrm{~mm}$ en la piel en el área receptora para realizar la lipo-injerto. La infiltración de grasa se hace con jeringas y cánulas romas con fenestra terminal, de diámetros internos de 1.2, 0.9 y 0.7. La grasa se deposita en diferentes camadas en la región subcutánea.

Se hace el curativo no compresivo y los pacientes reciben orientaciones de no realizar presión sobre el área del injerto durante mínimo 10 días después del procedimiento.

La documentación se realiza por medio de prontuario y fotografías. Estas son realizadas en incidencias de frente, perfil, oblicua $y$ otras que sean convenientes, durante el pre, trans $y$ pos operatorio de 1,3, 6 y 12 meses.

\section{Resultados}

Caso 1: Paciente de 23 años diagnosticada como Síndrome de ParryRomberg. Durante el examen físico presentaba atrofia de musculatura malar, zigomática y labial con poco tejido celular subcutáneo e híper pigmentación de la piel del mismo lado del rostro. Se realizó el tratamiento de lipo-injerto en la región acometida.

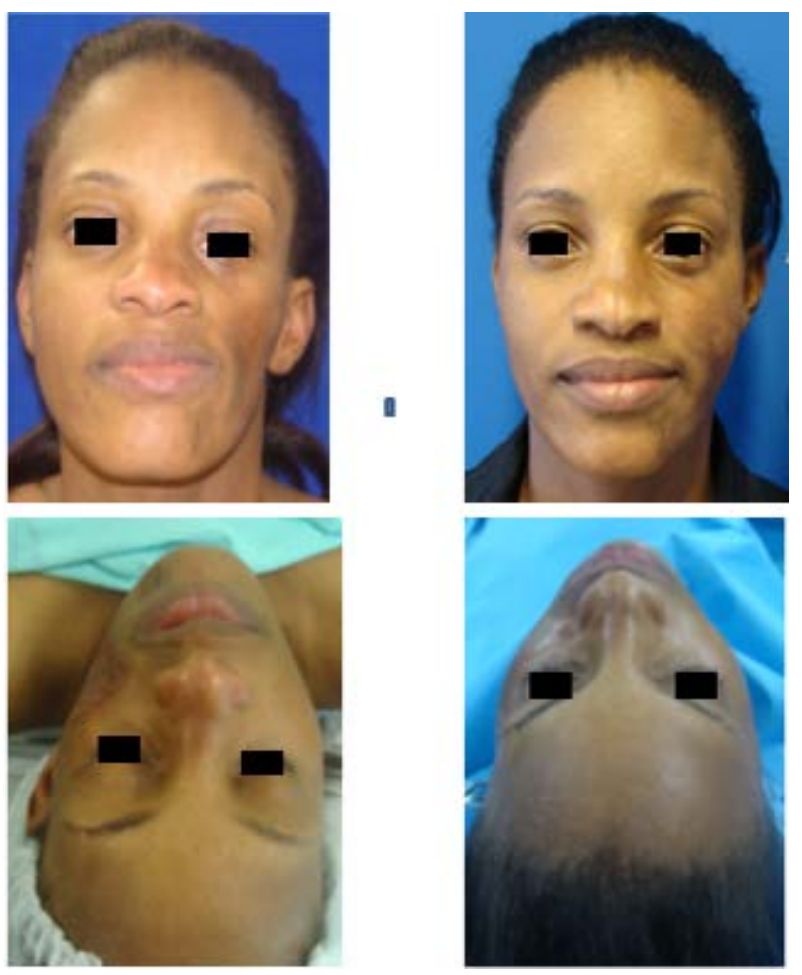

Caso 2: Paciente sometida en otro servicio por dos sesiones de lipoinjerto en la región malar con grasa retirada de la región abdominal. Evolucionó con un aumento ponderal de $12 \mathrm{~kg}$ después del procedimiento presentado con un aumento expresivo de la región operada. No se sabe cuál fue la técnica que fue utilizada para esos injertos. Fue realizada la liposucción parsimoniosa del área abombada y lipo-injerto en las áreas retraídas. Esperando un segundo tiempo quirúrgico. 

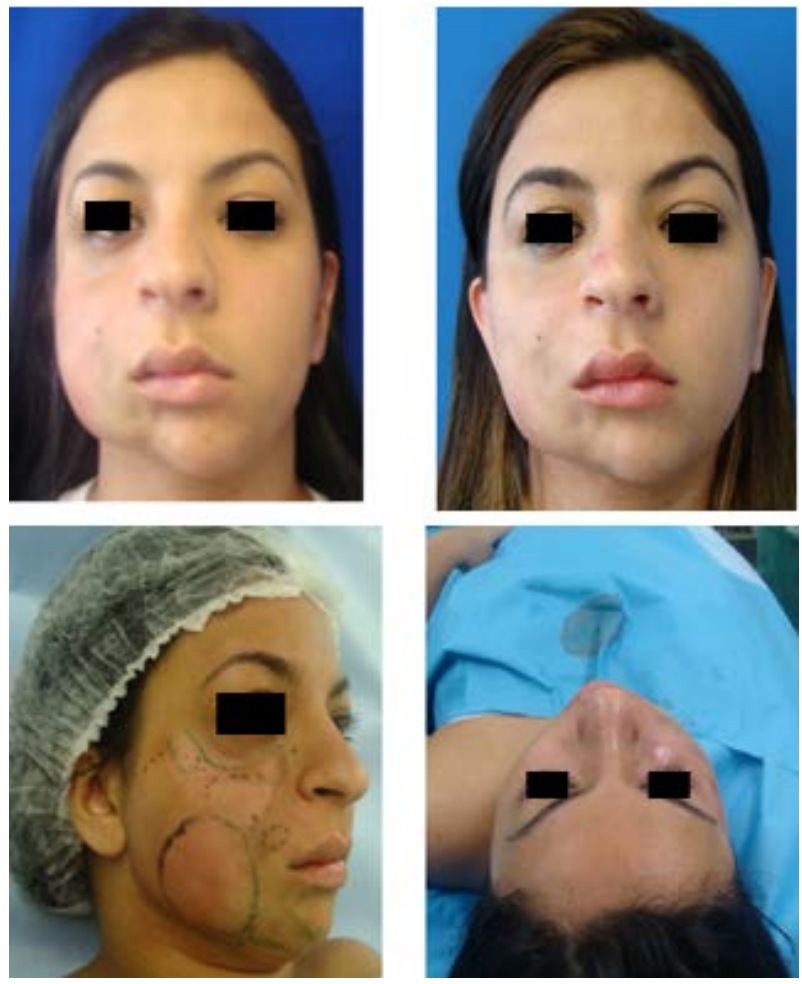

Caso 3: Paciente de 24 años que fue sometida a una hepatectomía parcial a los 2 años y evolucionó con una depresión en la región de HCD. Fue realizado un tratamiento con liposucción de flancos y lipo-injerto en el área acometida.
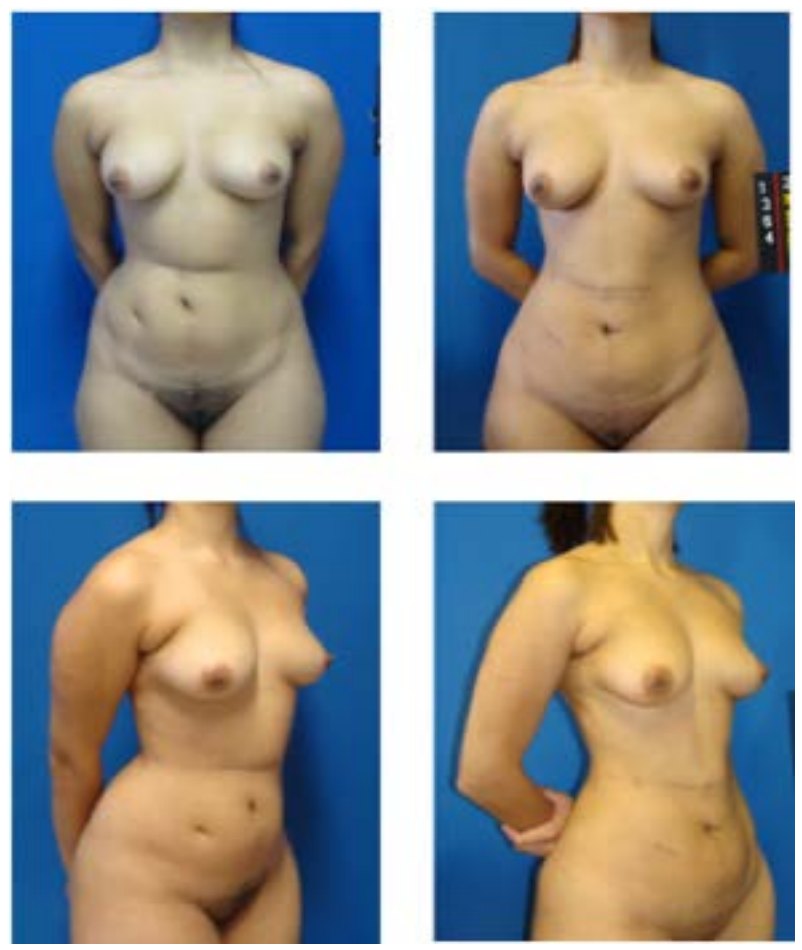

Caso 4: Paciente de 45 años víctima de atropellamiento con lesión en MID con pérdida de la substancia evolucionó con una cicatriz deprimida en el local. Fue realizado un tratamiento de lipo-injerto en la región de la cicatriz.
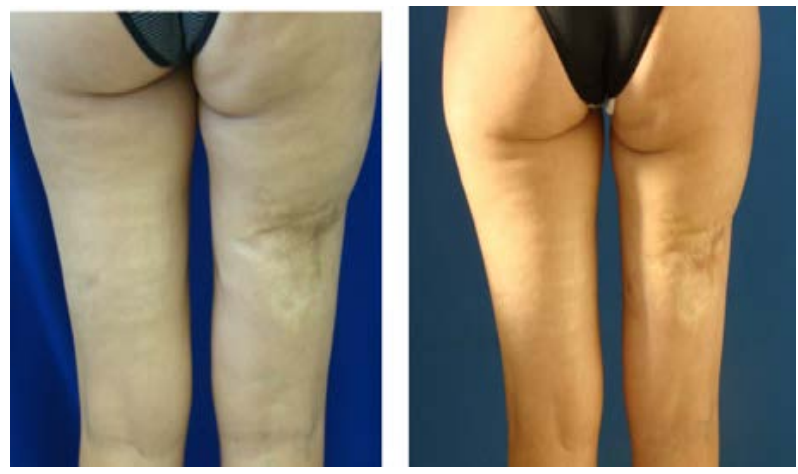

Caso 05 Paciente de 56 años sometida a mandibulectomia parcial inferior a la izquierda debido a un tumor en la boca en otro servicio. Fue realizado un relleno local con lipo-injerto.
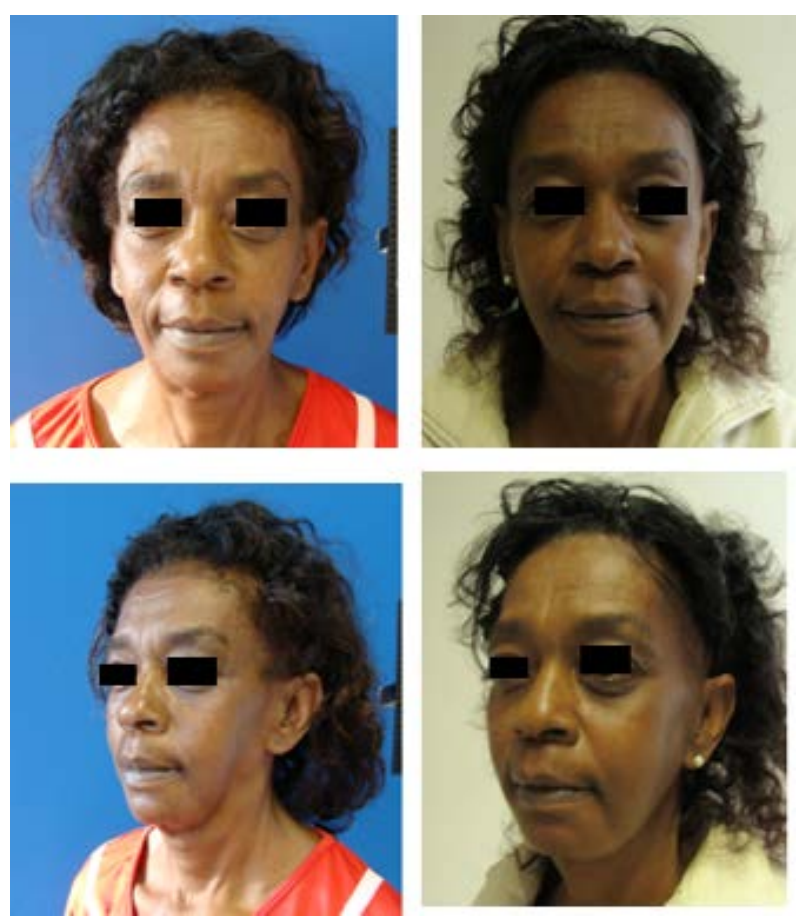

No fueron encontradas complicaciones como infecciones, dolores expresivos $u$ otros relacionados al procedimiento, en un año de la aplicación. 
Notamos que además de la mejoría en las retracciones cicatriciales y el aumento del volumen en áreas de depresión, la infiltración de grasa proporcionó la mejoría de la calidad de la piel. El volumen de grasa parece que necesita aproximadamente de 3 meses para estabilizarse. Con el acompañamiento de hasta un ano, notamos que a través de un examen físico y de fotografías, hubo poca reabsorción del injerto y mantenimiento del volumen.

El equipo y los pacientes quedaron satisfechos con el resultado obtenido.

\section{Discusión}

El procedimiento de lipo-injerto, es de complejidad técnica baja/moderada cuando existe una estandarización de recolección, preparación e infiltración de la grasa y se realiza por un cirujano capacitado.

Las complicaciones con injertos de grasa no son frecuentes. Las más citadas son dolores, infecciones y aspecto antiestético. Durante todo el procedimiento, se mantiene bajo observación la técnica estéril y la succión inmediatamente antes de la infiltración de grasa, evitando de esta forma posibles lipo embolias. No se reportaron inyecciones intravenosas con el uso de cánulas romas en la literatura $^{11}$, debido a esto, utilizamos siempre ese tipo de cánulas. Pocos casos literarios fueron encontrados mostrando un aumento expresivo de la grasa injertada con o sin aumento de peso ${ }^{12-13}$

Una investigación realizada en 2007 por miembros de la American Society for Aesthetic Plastic Surgery, mostró que la técnica difundida por Coleman era la más común para transferencias de grasa (54\%), seguida por la liposucción clásica (25\%), otras técnicas con jeringas (16\%) y escisión directa (5\%) 14

Recientes estudios demostraron que la succión de adipocitos con cánulas ciegas y la centrifugación de los mismos, presentan una tasa de sobrevivencia de $90 \%$ de la grasa inyectada en estudios histológicos ${ }^{16-17}$. Sin embargo, más estudios son necesarios para determinar la tasa de sobrevivencia en seres vivos.

\section{Conclusión}

A través de exámenes clínicos de los pacientes sometidos al procedimiento en nuestro servicio, fue posible comprobar resultados satisfactorios y estimulantes en relación a la permanencia de la grasa injertada.

\section{Referencias}

1. Guyuron, B, and Majzoub, R.K. Facial augmentation with core fat graft: a preliminary report. Plastic and reconstructive surgery 120.1 (2007): 295-302.

2. Coleman, $S$ R. Structural fat grafting: more than a permanent filler. Plastic and reconstructive surgery $118.3 \mathrm{~S}$ (2006): 108S-120S.

3. Illouz, Y. G. The fat cell "graft": A new technique to fill depressions. Plast. Reconstr. Surg. 78: 122, 1986.

4. Lambros, V. Fat injection for the aging midface. Operative Techniques in Plastic and Reconstructive Surgery 5.2 (1998): 129-137.

5. Coleman, S. R. Long-term survival of fat transplants: Controlled 
demonstrations. Aesthetic Plast. Surg. 19: 421, 1995.

6.Coleman, S. R. The technique of periorbital lipoinfiltration. Oper. Tech. Plast. Reconstr. Surg. 1: 20, 1994.

7. Coleman, S. R. Facial recontouring with lipostructure. Clin. Plast. Surg. 24: 347, 1997.

8. Sommer, B., and Sattler, G. Current concepts of fat graft survival: Histology of aspirated adipose tissue and review of the literature. Dermatol. Surg. 26: 1159, 2000.

9. Ullmann, Y., Hyams, M., Ramon, Y., Beach, D., Peled, I. J., and Lindenbaum, E. S. Enhancing the survival of aspirated human fat injected into nude mice. Plast. Reconstr. Surg. 101: 1940, 1998.

10.Shoshani, O., Livne, E., Armoni, M., et al. The effect of interleukin- 8 on the viability of injected adipose tissue in nude mice. Plast. Reconstr. Surg. 115: 853, 2005.

11.Coleman, S. R. Avoidance of arterial occlusion from injection of soft tissue fillers. Aesthetic Surg. J. 22: 555, 2002.

12.Latoni, J. D., Marshall, D. M., and Wolfe, S. A. Overgrowth of fat autotransplanted for correction of localized steroidinduced atrophy. Plast. Reconstr. Surg. 106: 1566, 2000.

13.Miller, J. J., and Popp, J. C. Fat hypertrophy after autologous fat transfer. Ophthal. Plast. Reconstr. Surg. 18: 228, 2002.

14.Kaufman, M. R., Bradley, J. P., Dickinson, B., et al. Autologous fat transfer national consensus survey: Trends in techniques for harvest, preparation, and application, and perception of short- and long-term results. Plast. Reconstr. Surg. 119: 323, 2007.

15.Coleman, S R. Long-term survival of fat transplants: controlled demonstrations. Aesthetic plastic surgery 19.5 (1995): 421-425.

16.Von Heimburg, D., Hemmrich, K., Haydarlioglu, S., et al. Comparison of viable cell yield from excised versus aspirated adipose tissue. Cells Tissues Organs 178: 87, 2004.

17.Jauffret, J. L., Champsaur, P., Robaglia-Schlupp, A., et al. Arguments in favor of adipocyte grafts with the S.R.Colemantechnique (en Francés). Ann. Chir. Plast. Esthet.46: 31, 2001. 